\title{
Freqüência de híbridos em cruzamentos controlados de citros: cultivo de sementes versus cultivo in vitro de embriões ${ }^{(1)}$
}

\author{
Walter dos Santos Soares Filho ${ }^{(2)}$, Antonio Carlos de Morais Medrado(3), Mario Augusto Pinto da Cunha ${ }^{(2)}$, \\ Almir Pinto da Cunha Sobrinho ${ }^{(2)}$ e Orlando Sampaio Passos ${ }^{(2)}$
}

\begin{abstract}
Resumo - Os objetivos deste trabalho foram estudar a freqüência de híbridos oriundos de cruzamentos controlados em citros, comparando a germinação de sementes em canteiros com o cultivo in vitro de embriões, e analisar o efeito da remoção dos tegumentos da semente na germinação. Como parentais femininos foram utilizadas as tangerineiras 'Clementina Palazelli' e 'Sunki', os limoeiros 'Cravo Santa Bárbara' e 'Volkameriano Catânia 2' e as laranjeiras Azedas 'Comum' e 'Double Calice'. Os parentais masculinos compreenderam Poncirus trifoliata e híbridos desta espécie. No cultivo das sementes em canteiros foi usado o delineamento experimental inteiramente casualizado, considerando-se os tratamentos de semente: íntegra; sem o tegumento externo (testa); e sem os tegumentos externo e interno (tégmen). O cultivo in vitro de embriões foi empregado como controle. Avaliou-se: velocidade de germinação das sementes, porcentagem de germinação e de poliembrionia, tamanho e número de embriões por semente, e porcentagem de híbridos. A remoção dos tegumentos das sementes acelerou o início de germinação de todas as variedades; afetou favorável e significativamente a porcentagem de germinação somente em tangerineira 'Sunki' e em limoeiro 'Volkameriano'. A porcentagem de indivíduos zigóticos resgatados foi maior no cultivo in vitro de embriões. A vantagem de uso desta técnica é diretamente proporcional ao grau de poliembrionia dos parentais femininos empregados nos cruzamentos.
\end{abstract}

Termos para indexação: poliembrionia, tegumento da semente, germinação, métodos de melhoramento.

\section{Frequency of citrus hybrids from controlled crossings: seed germination in seedbeds versus in vitro embryo cultivation}

\begin{abstract}
The frequency of citrus hybrids obtained from controlled crossings was studied, comparing seed germination in seedbeds with embryos cultivated in vitro. The effect of peeling off the seed teguments on the germination was also studied. The 'Clementina Palazelli' and 'Sunki' mandarins, 'Rangpur Santa Bárbara' lime, 'Volkamer Catania 2' lemon and sour oranges 'Common' and 'Double Calice' were used as female parents. The male parents were Poncirus trifoliata and hybrids of this species. A completely randomized design was used, with three seed treatments: intact; without the outer tegument (testa); and, without both the outer and inner (tegmen) teguments. The in vitro embryo culture was used as control. Evaluations included the speed of seed germination, percentage of germination and polyembryony, size and number of embryos per seed and percentage of hybrid seedlings. The removal of seed teguments accelerated the germination in all varieties; improved the percentage of germination only in 'Sunki' mandarin and 'Volkamer' lemon. The percentage of zygotic seedlings that were rescued was higher in the in vitro embryo culture, in such a way that the advantage in using this technique was directly proportional to the degree of polyembryony of the female parents used in the crosses.
\end{abstract}

Index terms: polyembryony, testa, germination, breeding methods.

\footnotetext{
(1) Aceito para publicação em 14 de setembro de 2001.

(2) Embrapa-Centro Nacional de Pesquisa de Mandioca e Fruticultura Tropical, Caixa Postal 007, CEP 44380-000 Cruz das Almas, BA. E-mail: wsoares@cnpmf.embrapa.br, maugusto@cnpmf.embrapa.br, almir@cnpmf.embrapa.br, orlando@cnpmf.embrapa.br

(3) Colégio Estadual Alberto Torres, Rua Manoel Caetano Passos, 141, CEP 44380-000 Cruz das Almas, BA.
}

\section{Introdução}

Os programas de melhoramento genético de citros têm na poliembrionia, na alta heterozigose e no longo período pré-reprodutivo os principais obstáculos à criação intencional de novas variedades.

A poliembrionia é um fenômeno comum a muitas espécies cítricas, caracterizando-se pela presença de 
mais de um embrião numa mesma semente. A maioria desses embriões é de origem nucelar (apogâmicos), sendo o embrião zigótico, quando presente, geralmente único.

A presença de vários embriões numa mesma semente pode dificultar a sobrevivência dos embriões zigóticos, devido à competição que os embriões de origem assexuada estabelecem com aqueles de origem sexuada. Assim, em um programa de melhoramento genético de citros visando à obtenção de um maior número possível de híbridos, é aconselhável, em cruzamentos empregando parentais femininos poliembriônicos, particularmente nas situações em que a porcentagem de poliembrionia é elevada, a excisão dos embriões das sementes resultantes das hibridações realizadas, seguida de seu cultivo in vitro, de modo a garantir a germinação e desenvolvimento da maioria das plântulas, separando, posteriormente, os indivíduos de natureza híbrida dos nucelares.

Em cruzamentos controlados utilizando parentais com diferentes graus de poliembrionia, Vásquez Araujo (1991), Soares Filho et al. (1994), Moreira (1996) e Soares Filho et al. (2000) constataram que o embrião zigótico tende a encontrar-se no grupo de embriões de maior tamanho, sendo essa situação tanto mais evidente quanto menor for o grau de poliembrionia do parental feminino empregado.

Os objetivos deste trabalho foram verificar a possibilidade de evitar, em variedades com graus de poliembrionia entre nulo a moderado, o cultivo in vitro de embriões, sem prejuízos à sobrevivência de híbridos, e avaliar o efeito da remoção dos tegumentos da semente na germinação.

\section{Material e Métodos}

O trabalho foi realizado na Embrapa-Centro Nacional de Pesquisa de Mandioca e Fruticultura Tropical, em Cruz das Almas, BA. No período de setembro a dezembro de 1995, com base em acessos do Banco Ativo de Germoplasma de Citros, foram efetuadas polinizações controladas, mantendo a individualidade dos parentais femininos e masculinos. Considerando a classificação do grau de poliembrionia proposta por Cameron \& Soost (1976), as seguintes variedades foram utilizadas como parentais femininos: tangerineira 'Clementina Palazelli' (Citrus clementina Hort. ex Tan.), monoembriônica; tangerineira
'Sunki' (C. sunki Hort. ex Tan.), baixa poliembrionia; limoeiro 'Cravo Santa Bárbara' (C. limonia Osb.), baixa a moderada poliembrionia; limoeiro 'Volkameriano Catânia 2' (C. volkameriana Ten. et Pasq.), alta poliembrionia; laranjeira 'Azeda Comum' (C. aurantium L.), alta poliembrionia; laranjeira 'Azeda Double Calice', muito alta poliembrionia. Em razão da presença da característica trifoliada, dominante e de fácil identificação visual, foram empregadas como parentais masculinos as variedades Poncirus trifoliata (L.) Raf. seleções Beneke, Rubidoux, Pomeroy e Flying Dragon; citranges [C. sinensis (L.) Osb. $\mathrm{x}$ P. trifoliata] Argentina, Troyer, Rusk e C-35; citrumelo (C. paradisi Macf. x P. trifoliata) Swingle.

Pólen colhido de flores recém-abertas dos parentais masculinos foi utilizado na polinização de flores dos parentais femininos; estas últimas foram emasculadas antes da antese. A emasculação foi efetuada em botões florais próximos da abertura (estádio de balão), eliminandose cuidadosamente as pétalas e anteras com o auxílio de pinça e bisturi, e evitando-se o contato com o estigma. Em todos os casos, a polinização ocorreu imediatamente após a emasculação, estando o estigma receptivo (úmido). As flores polinizadas foram protegidas com sacos de gaze, os quais foram retirados 30 dias após a polinização, momento em que se verificou o vingamento dos frutos.

Os frutos foram colhidos oito a nove meses após a polinização. Suas sementes foram cuidadosamente removidas, eliminando-se as malformadas, separando-as em dois grupos: um, dirigido ao cultivo em canteiros móveis de isopor, sob condições de casa de vegetação, e outro, ao cultivo in vitro de embriões. Nos canteiros foram aplicados três tratamentos: semente íntegra, semente sem o tegumento externo (testa) e semente sem os tegumentos externo e interno (tégmen). Após lavagem em água destilada, parte das sementes foram secadas em papel toalha, sendo a seguir submetidas à extração manual de um ou ambos tegumentos, enquanto as que seriam semeadas integralmente foram desinfetadas em uma solução de hipoclorito de sódio a $3 \%$ (v/v) durante 20 minutos. Os canteiros continham 72 células, as quais foram preenchidas com substrato esterilizado composto de terra vegetal + vermiculita na proporção de $3: 1$, sendo cada tratamento distribuído em 24 células. As sementes separadas para o cultivo in vitro de embriões foram lavadas com solução de água e detergente, secadas e despojadas do tegumento externo, manualmente. A seguir, sob condições assépticas, em câmara de fluxo de ar laminar estéril, foram tratadas com uma solução de etanol $70 \%$ durante cinco minutos e posteriormente em hipoclorito de sódio $2 \%(\mathrm{v} / \mathrm{v})$ por 20 minutos. Após essas etapas de preparação das sementes, efetuaram-se duas e três lavagens sucessivas com água destilada autoclavada, respectivamente. 
Em relação às sementes cultivadas em canteiros de isopor, o delineamento experimental utilizado foi o inteiramente casualizado. O número de repetições foi variável segundo o número de sementes disponíveis: três repetições para a tangerineira 'Sunki', laranjeira 'Azeda' seleção 'Comum' e limoeiros ‘Cravo' e 'Volkameriano', quatro para a laranjeira 'Azeda' seleção 'Double Calice' e seis para a tangerineira 'Clementina'.

Nos dois primeiros meses de cultivo, os canteiros foram irrigados com água destilada, com o propósito de evitar a incidência de fungos de solo causadores de estiolamento de sementeira (tombamento das plantas). O registro de emergência das plântulas e a identificação de híbridos com base no formato trifoliado do limbo foliar foram feitos diariamente. Nessa ocasião foram avaliados o período de germinação das sementes - pela contagem diária das sementes germinadas [sementes que apresentaram emissão de plântula(s)] - e a porcentagem de germinação. Os dados relativos aos caracteres porcentagem de germinação, índice de velocidade de emergência de plântula este, determinado pela fórmula de Maguire (1962), citada por Vieira \& Carvalho (1994) - e porcentagem de indivíduos zigóticos foram submetidos a análises de variância; os relativos à porcentagem de germinação foram transformados em arco seno, $(\mathrm{v} / 100)^{0,5}$, visando à normalidade dos dados, onde v refere-se ao valor observado.

Quanto ao cultivo in vitro de embriões, a excisão destes das sementes foi realizada sob estereomicroscópio equipado com uma fonte luminosa, com o auxílio de bisturi, pinça e estilete. Mediante corte longitudinal, a certa distância da região micropilar da semente para evitar lesões aos embriões, procedeu-se à remoção do tegumento interno. $\mathrm{O}$ cultivo dos embriões deu-se em sala de crescimento, a $27 \pm 1^{\circ} \mathrm{C}$, com 16 horas/dia de iluminação a uma intensidade de 1.500 lux, fornecida por lâmpadas fluorescentes de $40 \mathrm{~W}$, em meio MT (Murashige \& Tucker, 1969), com modificações nos teores de caseína hidrolisada $(500 \mathrm{mg} / \mathrm{L})$, ácido naftalenoacético (ANA, 0,02 mg/L), benzilaminopurina (BAP, 0,04 mg/L) e de ágar-ágar $(0,7 \%)$ (Vásquez Araujo, 1991; Soares Filho et al., 1994). Esta etapa do estudo foi realizada sem delineamento experimental, com o propósito de obter as freqüências de híbridos a serem comparadas com as constatadas no cultivo de sementes em canteiros de isopor. Neste caso, o tamanho das amostras foi variável, em razão da disponibilidade de sementes: 72 sementes da tangerineira 'Clementina', limoeiro 'Volkameriano' e laranjeira 'Azeda Comum'; 48 sementes da tangerineira 'Sunki' e da laranjeira 'Azeda Double Calice'. O limoeiro 'Cravo' foi excluído desta avaliação dado o número insuficiente de sementes disponíveis.

Simultaneamente às excisões, foram feitas a contagem e a classificação dos embriões com relação ao tamanho, me- diante o auxílio de papel milimetrado esterilizado. Os embriões de cada semente foram agrupados em quatro classes distintas de tamanho: classe 1: embriões muito pequenos (MP): $<1,0 \mathrm{~mm}$; classe 2 : embriões pequenos $(\mathrm{P}): 1,0 \mathrm{~mm}$ a $2,9 \mathrm{~mm}$; classe 3 : embriões médios $(\mathrm{M})$ : $3,0 \mathrm{~mm}$ a $4,9 \mathrm{~mm}$; classe 4 : embriões grandes $(\mathrm{G})$ : $\geq 5,0 \mathrm{~mm}$. A poliembrionia foi avaliada considerando-se o número médio de embriões por semente e a porcentagem de poliembrionia.

Após dois meses de cultivo in vitro, as plantas foram transplantadas para canteiros de isopor, colocadas em casa de vegetação, para avaliação da forma do limbo foliar, visando à obtenção da freqüência observada de híbridos (indivíduos trifoliados) em relação a cada parental feminino, no intuito de comparar esses resultados com os obtidos a partir do cultivo das sementes em canteiros.

\section{Resultados e Discussão}

Foram executadas 656 polinizações: 169 em tangerineira 'Clementina', 126 em tangerineira 'Sunki', 88 em limoeiro 'Cravo', 93 em limoeiro 'Volkameriano', 93 em laranjeira 'Azeda Comum' e 87 em laranjeira 'Azeda Double Calice'. As taxas de vingamento de frutos obedeceram à seguinte ordem decrescente: $46,0 \%$ na tangerineira 'Sunki', $39,1 \%$ na laranjeira 'Azeda Double Calice', 37,5\% no limoeiro 'Cravo', 24,8\% na tangerineira 'Clementina', 20,4\% na laranjeira 'Azeda Comum' e 19,4\% no limoeiro 'Volkameriano'. Vásquez Araujo (1991) e Moreira (1996), realizando polinizações controladas em limoeiro 'Cravo' e também empregando $P$. trifoliata e híbridos desta espécie como parentais masculinos, obtiveram taxas de vingamento de frutos de 55,6\% e $16,8 \%$, respectivamente. Moreira (1996), além disso, constatou taxas de vingamento de frutos de $21,7 \%$ na tangerineira 'Clementina', $37,1 \%$ na tangerineira 'Sunki' e 21,0\% no limoeiro 'Volkameriano'. Entre as possíveis causas de tais diferenças, pode-se citar a ocorrência de variações ambientais, relacionadas particularmente à temperatura e à freqüência de chuvas e sua intensidade, além da capacidade de combinação dos parentais envolvidos nas hibridações (Soares Filho et al., 2000).

O número médio de sementes por fruto obedeceu à seguinte ordem decrescente: 26,3 na laranjeira 'Azeda Comum', 21,2 no limoeiro 'Volkameriano', 16,6 na tangerineira 'Clementina', 13,8 na laranjeira 'Azeda Double Calice', 7,6 no limoeiro 'Cravo' e 5,7 na 
tangerineira 'Sunki'. O comportamento desse caráter, embora inerente a cada espécie ou cultivar (Moreira et al., 1947), pode ser influenciado por fatores ambientais, a exemplo dos parentais masculinos envolvidos nas polinizações (Wong, 1939; Moreira \& Gurgel, 1941); a ocorrência de médias de sementes por fruto relativamente altas indica boa compatibilidade entre os parentais envolvidos nas hibridações.

Os graus de poliembrionia dos parentais femininos variaram desde praticamente nulos (tangerineiras 'Clementina' e 'Sunki') a muito alto (laranjeira 'Azeda Double Calice') (Tabela 1).

As médias de embriões por semente aproximaram-se das obtidas por Moreira (1996), que encontrou valores de 1,01 em tangerineira 'Clementina', 1,26 em tangerineira 'Sunki' e 2,80 em limoeiro 'Volkameriano', com intervalos de variação do número de embriões por semente de 1 a 3, de 1 a 13 e de 1 a 8 com relação às respectivas cultivares.

O número médio de embriões por semente varia, tanto entre como dentro de espécies, em virtude das influências do meio ambiente - a exemplo da temperatura e condições nutricionais - e dos genótipos envolvidos nas hibridações (Parlevliet \& Cameron, 1959; Cameron \& Soost, 1979; Soares Filho et al., 1995a). Moreira et al. (1947) encontraram sementes de laranja-doce contendo até 15 embriões, enquanto Dubey \& Rishi (1976) e Nakatani et al. (1980) registraram recordes de 40 e 107 embriões em sementes de tangerinas, respectivamente. Variações na taxa de poliembrionia também são verificadas. Pesquisas realizadas com limoeiro 'Cravo' constataram taxas de poliembrionia entre 13\% e 89\% (Moreira et al., 1947;
Soares Filho et al., 1991, 1994; Vásquez Araujo, 1991). Soares Filho et al. (1995a) indicaram a ocorrência de taxa de poliembrionia em tangerineira 'Sunki' superior a $10 \%$, enquanto no limoeiro 'Volkameriano', à semelhança do que ocorreu neste estudo, as sementes poliembriônicas superaram a taxa de $70 \%$. Moreira (1996) obteve 1,4\% de sementes poliembriônicas em tangerineira 'Clementina', $15,9 \%$ em tangerineira 'Sunki', 35,2\% em limoeiro 'Cravo' e 58,6\% em limoeiro 'Volkameriano'. Esses trabalhos basearam-se em contagens diretas do número de embriões presentes nas sementes, a exemplo do que se deu neste estudo.

Em todas as variedades estudadas, constatou-se que a maior freqüência de embriões ocorreu na classe de tamanho grande $(\geq 5,0 \mathrm{~mm})$ (Tabela 2$)$. Confrontando-se estes dados com os da Tabela 1 , verifica-se uma relação inversa entre o grau de poliembrionia e a freqüência de embriões de maior tamanho, confirmando resultados obtidos por Vásquez Araujo (1991), Soares Filho et al. (1994), Moreira (1996) e Soares Filho et al. (2000). Frost \& Soost (1968) e Diaz et al. (1979) comentam que o desenvolvimento de um número reduzido de embriões por semente induz a um aumento no tamanho dos embriões, favorecendo a germinação dos eventuais embriões zigóticos e, portanto, a sobrevivência dos híbridos.

O início de germinação das sementes e a velocidade de emergência de plântulas foram favorecidos pela remoção dos tegumentos das sementes em todas as variedades, o que confirma resultados obtidos por Soares Filho et al. (1995b) (Tabela 3).

A porcentagem de germinação foi influenciada significativamente pela remoção do tegumento ex-

Tabela 1. Número de sementes amostradas (NSA), número médio de embriões por semente (NMES), intervalo de variação do número de embriões por semente (IVNES), porcentagem e classificação da poliembrionia, relativos a cinco variedades cítricas. Cruz das Almas, BA, 1996.

\begin{tabular}{|c|c|c|c|c|c|c|}
\hline \multirow[t]{2}{*}{ Variedade $^{(1)}$} & \multirow[t]{2}{*}{ NSA } & \multirow[t]{2}{*}{ NMES } & \multicolumn{2}{|c|}{ IVNES } & \multicolumn{2}{|c|}{ Poliembrionia } \\
\hline & & & Mínimo & Máximo & $\%$ & Classificação $^{(2)}$ \\
\hline TCL & 72 & 1,07 & 1 & 2 & 1,5 & $\mathrm{Mn}$ \\
\hline TSK & 48 & 1,15 & 1 & 3 & 8,3 & $\mathrm{Mn}$ \\
\hline LVK & 72 & 2,60 & 1 & 6 & 79,2 & A \\
\hline LAC & 72 & 2,56 & 1 & 7 & 76,4 & A \\
\hline LADC & 48 & 4,29 & 1 & 8 & 90,5 & MA \\
\hline
\end{tabular}

(1)TCL: tangerineira 'Clementina'; TSK: tangerineira 'Sunki'; LVK: limoeiro 'Volkameriano'; LAC: laranjeira 'Azeda Comum'; LADC: laranjeira 'Azeda Double Calice'. ${ }^{(2)} \mathrm{Mn}$ : monoembriônica; A: poliembrionia alta; MA: poliembrionia muito alta (segundo classificação de Cameron \& Soost, 1979). 
terno (S-1) na tangerineira 'Sunki' e pela remoção dos tegumentos externo e interno (S-2) no limoeiro 'Volkameriano', enquanto nas demais variedades esse efeito não foi significativo (Tabela 4). A remoção dos tegumentos favoreceu a velocidade de emergência de plântulas, em todas as variedades estudadas, mas em relação à laranjeira 'Azeda Comum', esse efeito só ocorreu quando foram removidos os dois tegumentos da semente. Os tegumentos das sementes não influenciaram o porcentual de indivíduos trifoliados.

A distinção entre indivíduos zigóticos e nucelares foi realizada com base na característica trifoliada de Poncirus, usada como marcador morfológico. As freqüências de híbridos trifoliados relativamente mais elevadas obtidas nas tangerineiras 'Clementina' $(51,5 \%)$ e 'Sunki' (48,6\%) (Tabela 5) deveram-se, provavelmente, à baixa porcentagem de sementes poliembriônicas, ao reduzido número médio de embriões por semente (Tabela 1) e à relativamente elevada porcentagem de embriões de maior tamanho apresentados por essas tangerineiras (Tabela 2). A esse respeito, vários autores citam que o desenvolvimento de um número reduzido de embriões por semente induz a um aumento no tamanho dos embriões zigóticos, favorecendo sua germinação e, conseqüentemente, a sobrevivência dos híbridos (Frost \& Soost, 1968; Diaz et al., 1979; VásquezAraujo, 1991; Soares Filho et al., 1994; Moreira, 1996; Soares Filho et al., 2000).

Considerando-se o cultivo in vitro de embriões, as maiores porcentagens de indivíduos zigóticos (trifoliados) foram constatadas nas tangerineiras 'Clementina' (56,2\%) e 'Sunki' (51,1\%), seguindo-se, em ordem decrescente, a laranjeira 'Azeda Comum' (17,4\%), limoeiro 'Volkameriano' (16,3\%) e laranjeira

Tabela 2. Classificação dos embriões de cinco variedades cítricas, segundo seu tamanho, com base em amostras de sementes obtidas de cruzamentos controlados envolvendo essas variedades como parentais femininos, tendo como parentais masculinos Poncirus trifoliata e híbridos desta espécie. Cruz das Almas, BA, 1996.

\begin{tabular}{|c|c|c|c|c|c|c|c|c|c|}
\hline \multirow[t]{3}{*}{ Variedade $^{(1)}$} & \multirow{3}{*}{$\begin{array}{l}\text { Totais de } \\
\text { embriões } \\
\text { excisados }\end{array}$} & \multicolumn{8}{|c|}{ Classes de tamanho de embrião ${ }^{(2)}$} \\
\hline & & \multicolumn{2}{|c|}{ G } & \multicolumn{2}{|c|}{ M } & \multicolumn{2}{|c|}{$\mathrm{P}$} & \multicolumn{2}{|c|}{ MP } \\
\hline & & № & $\%$ & № & $\%$ & № & $\%$ & № & $\%$ \\
\hline TCL & 77 & 72 & 93,5 & 4 & 5,2 & 1 & 1,3 & 0 & 0,0 \\
\hline TSK & 54 & 45 & 83,3 & 3 & 5,6 & 4 & 7,4 & 2 & 3,7 \\
\hline LVK & 187 & 135 & 72,2 & 32 & 17,1 & 16 & 8,6 & 4 & 2,1 \\
\hline LAC & 184 & 137 & 74,5 & 30 & 16,3 & 12 & 6,5 & 5 & 2,7 \\
\hline LADC & 206 & 78 & 37,9 & 51 & 24,8 & 50 & 24,3 & 27 & 13,1 \\
\hline
\end{tabular}

(1)TCL: tangerineira 'Clementina'; TSK: tangerineira 'Sunki'; LVK: limoeiro 'Volkameriano'; LAC: laranjeira 'Azeda Comum'; LADC: laranjeira 'Azeda Double Calice'. ${ }^{(2)} \mathrm{G}$ : grande ( $\left.\geq 5,0 \mathrm{~mm}\right)$; M: médio (3,0 mm a 4,9 mm); P: pequeno (1,0 mm a 2,9 mm); MP: muito pequeno (<1,0 mm).

Tabela 3. Número total de sementes amostradas (TSA), porcentagem de germinação (G), início da germinação (IG) em dias após a semeadura e índice de velocidade de emergência de plântula (IVE) em seis variedades cítricas, considerando a semente íntegra (S-0), sem o tegumento externo (S-1) e sem os tegumentos externo e interno (S-2). Cruz das Almas, BA, 1996-1997.

\begin{tabular}{|c|c|c|c|c|c|c|c|c|c|c|}
\hline \multirow[t]{2}{*}{ Variedade $^{(1)}$} & \multirow[t]{2}{*}{ TSA } & \multicolumn{3}{|c|}{ S-0 } & \multicolumn{3}{|c|}{ S-1 } & \multicolumn{3}{|c|}{ S-2 } \\
\hline & & G & IG & IVE & G & IG & IVE & G & IG & IVE \\
\hline TCL & 144 & 73,6 & 14 & 1,25 & 79,9 & 10 & 1,65 & 79,9 & 8 & 2,66 \\
\hline TSK & 72 & 84,7 & 17 & 0,94 & 100,0 & 16 & 1,25 & 94,4 & 9 & 2,23 \\
\hline LCR & 72 & 94,4 & 12 & 1,37 & 100,0 & 10 & 1,76 & 97,2 & 8 & 2,75 \\
\hline LVK & 72 & 84,7 & 25 & 0,90 & 87,5 & 12 & 1,33 & 95,8 & 12 & 1,92 \\
\hline LAC & 72 & 95,8 & 16 & 0,82 & 94,4 & 15 & 0,92 & 95,8 & 11 & 1,83 \\
\hline LADC & 96 & 93,8 & 21 & 0,83 & 96,9 & 19 & 1,03 & 99,0 & 11 & 1,83 \\
\hline
\end{tabular}

(1)TCL: tangerineira 'Clementina'; TSK: tangerineira 'Sunki'; LCR: limoeiro 'Cravo'; LVK: limoeiro 'Volkameriano'; LAC: laranjeira 'Azeda Comum'; LADC: laranjeira 'Azeda Double Calice'. 
'Azeda Double Calice' (13,1\%) (Tabela 6). Esses valores aproximam-se dos obtidos por Moreira (1996) em cruzamentos semelhantes, nos quais constatouse nas tangerineiras 'Clementina' e 'Sunki' e limoeiro 'Volkameriano' freqüências de híbridos de 57,4\%, $53,6 \%$ e 14,2\%, respectivamente. Em cruzamentos semelhantes aos do presente estudo, Vásquez Araujo (1991) e Moreira (1996), em cultivo in vitro, encontraram no limoeiro 'Cravo' uma freqüência de $18,6 \%$ de híbridos.

Esses resultados confirmam os que foram verificados no cultivo de sementes em canteiros, e reforçam o fato de que a freqüência de híbridos é inversamente proporcional ao grau de poliembrionia dos parentais utilizados.

Comparando-se as porcentagens de indivíduos zigóticos obtidas a partir do cultivo de sementes em canteiros de isopor (Tabela 5) com as do cultivo in vitro de embriões (Tabela 6), verifica-se que houve superioridade deste último, em todas as variedades. As diferenças em favor do cultivo in vitro foram de 4,7\% em tangerineira 'Clementina', $2,5 \%$ em tangerineira 'Sunki', 4,4\% em limoeiro 'Volkameriano', 5,2\% em laranjeira 'Azeda Comum' e de 1,9\% em laranjeira 'Azeda Double Calice'. Vásquez Araujo (1991) e Moreira (1996) obtiveram diferença de 2,4\% em favor do cultivo in vitro de embriões em relação ao limoeiro 'Cravo'. Essas diferenças, favoráveis ao cultivo in vitro de embriões, podem ser melhor percebidas com base no cálculo de porcentagens relativas (Tabela 7). À medida que o grau de poliembrionia dos parentais femininos aumenta (Tabela 1), tanto maior é a vantagem do cultivo in vitro de embriões sobre o cultivo de sementes em canteiros, relativamente à freqüência observada de indivíduos trifoliados (híbridos). Essa tendência só não foi evi-

Tabela 4. Valores médios relativos à porcentagem de germinação $(\mathrm{G})$ (transformados em arco seno), índice de velocidade de emergência de plântula (IVE) e porcentagem de indivíduos trifoliados (IT) obtidos a partir de sementes de seis variedades cítricas, considerando a semente íntegra (S-0), sem o tegumento externo (S-1) e sem os tegumentos externo e interno (S-2). Cruz das Almas, BA, 1996-1997(1).

\begin{tabular}{|c|c|c|c|c|c|c|c|c|c|c|c|c|}
\hline \multirow[t]{2}{*}{ Variedade $^{(2)}$} & \multicolumn{4}{|c|}{ G } & \multicolumn{4}{|c|}{ IVE } & \multicolumn{4}{|c|}{ IT } \\
\hline & S-0 & S-1 & S-2 & $\mathrm{CV}^{(3)}$ & S-0 & S-1 & S-2 & $\mathrm{CV}^{(3)}$ & S-0 & S-1 & S-2 & $\mathrm{CV}^{(3)}$ \\
\hline TCL & $0,50 \mathrm{a}$ & $0,50 \mathrm{a}$ & $0,48 \mathrm{a}$ & 4,2 & $1,25 \mathrm{c}$ & $1,65 b$ & $2,66 a$ & 3,5 & $11,0 \mathrm{a}$ & $11,6 a$ & $12,0 \mathrm{a}$ & 22,8 \\
\hline TSK & $0,47 b$ & $0,51 \mathrm{a}$ & $0,50 \mathrm{ab}$ & 2,5 & $0,94 \mathrm{c}$ & $1,25 b$ & $2,24 a$ & 4,9 & $10,0 \mathrm{a}$ & $10,6 a$ & $11,6 \mathrm{a}$ & 14,8 \\
\hline LCR & $0,51 \mathrm{a}$ & $0,50 \mathrm{a}$ & $0,50 \mathrm{a}$ & 14,0 & $1,38 \mathrm{c}$ & $1,76 b$ & $2,76 a$ & 2,5 & 3,6a & $3,6 \mathrm{a}$ & $4,0 \mathrm{a}$ & 29,3 \\
\hline LVK & $0,46 b$ & $0,48 b$ & $0,50 \mathrm{a}$ & 1,7 & $0,90 \mathrm{c}$ & $1,33 b$ & $1,62 \mathrm{a}$ & 5,3 & $2,7 \mathrm{a}$ & $2,7 \mathrm{a}$ & $2,5 \mathrm{a}$ & 26,5 \\
\hline LAC & $0,50 \mathrm{a}$ & $0,50 \mathrm{a}$ & $0,48 \mathrm{a}$ & 4,2 & $0,82 b$ & $0,92 b$ & $1,78 \mathrm{a}$ & 4,7 & $5,0 \mathrm{a}$ & $5,0 \mathrm{a}$ & $4,3 \mathrm{a}$ & 18,5 \\
\hline LADC & $0,51 \mathrm{a}$ & $0,50 \mathrm{a}$ & $0,49 a$ & 3,7 & $0,83 \mathrm{c}$ & $1,03 \mathrm{~b}$ & $1,83 \mathrm{a}$ & 4,6 & $3,0 \mathrm{a}$ & $2,5 \mathrm{a}$ & $2,3 \mathrm{a}$ & 3,6 \\
\hline
\end{tabular}

(1)Em cada parâmetro, médias seguidas das mesmas letras, na linha, não diferem significativamente entre si pelo teste de Tukey a $5 \%$ de probabilidade. (2)TCL: tangerineira 'Clementina'; TSK: tangerineira 'Sunki'; LCR: limoeiro 'Cravo'; LVK: limoeiro 'Volkameriano'; LAC: laranjeira 'Azeda Comum'; LADC: laranjeira ‘Azeda Double Calice’. ${ }^{(3)} \mathrm{CV}$ : coeficiente de variação (\%).

Tabela 5. Número total de sementes germinadas (NTS) e porcentagem de indivíduos trifoliados (IT) obtidos a partir do cultivo de sementes de seis variedades cítricas, considerando a semente íntegra (S-0), sem o tegumento externo (S-1) e sem os tegumentos externo e interno (S-2). Cruz das Almas, BA, 1996-1997.

\begin{tabular}{|c|c|c|c|c|c|c|c|c|}
\hline \multirow[t]{2}{*}{ Variedade $^{(1)}$} & \multicolumn{2}{|c|}{ S-0 } & \multicolumn{2}{|c|}{ S-1 } & \multicolumn{2}{|c|}{ S-2 } & \multicolumn{2}{|c|}{ Total geral } \\
\hline & NTS & IT & NTS & IT & NTS & IT & NTS & IT \\
\hline TCL & 106 & 51,8 & 115 & 50,4 & 115 & 52,2 & 336 & 51,5 \\
\hline TSK & 61 & 49,1 & 72 & 45,1 & 68 & 51,5 & 200 & 48,6 \\
\hline LCR & 68 & 16,2 & 72 & 15,3 & 70 & 17,1 & 210 & 16,2 \\
\hline LVK & 61 & 13,1 & 63 & 12,6 & 69 & 10,1 & 193 & 11,9 \\
\hline LAC & 69 & 11,1 & 68 & 11,1 & 69 & 14,5 & 206 & 12,2 \\
\hline LADC & 90 & 13,3 & 93 & 10,7 & 95 & 9,6 & 278 & 11,2 \\
\hline
\end{tabular}

(1)TCL: tangerineira 'Clementina'; TSK: tangerineira 'Sunki'; LCR: limoeiro 'Cravo'; LVK: limoeiro 'Volkameriano'; LAC: laranjeira 'Azeda Comum'; LADC: laranjeira 'Azeda Double Calice'. 
dente em relação à laranjeira 'Azeda Double Calice'. Presume-se que esse comportamento seja devido à ocorrência de fungos de solo (Rhizoctonia solani) nos canteiros, que provocaram a morte de plantas.

Considerando o conjunto de resultados obtidos, tem-se que, para variedades com graus de poliembrionia entre nulo a moderado, o cultivo de sementes em canteiros é preferível, por sua maior simplicidade e menores custos, uma vez que as eventuais perdas de híbridos, em relação ao cultivo in vitro de embriões, são pouco expressivas. Já para variedades com graus de poliembrionia elevados $(>70 \%)$, o cultivo in vitro de embriões mostra-se mais recomendável, pois favorece maior recuperação de híbridos.

Tabela 6. Número de sementes (NS) e embriões amostrados (NE), número total de indivíduos (NTI) e porcentagem de indivíduos trifoliados (IT) obtidos a partir do cultivo in vitro de embriões excisados de seis variedades cítricas. Cruz das Almas, BA, 1996-1997.

\begin{tabular}{lrrrc}
\hline Variedade $^{(1)}$ & NS & NE & NTI & IT \\
\hline TCL & 72 & 77 & 48 & 56,2 \\
TSK & 48 & 55 & 45 & 51,1 \\
LCR $^{(2)}$ & 1.217 & 2.448 & 2.000 & 18,6 \\
LCR $^{(3)}$ & 193 & 291 & 210 & 18,6 \\
LVK & 72 & 187 & 43 & 16,3 \\
LAC & 72 & 184 & 69 & 17,4 \\
LADC & 48 & 206 & 61 & 13,1 \\
\hline
\end{tabular}

(1)TCL: tangerineira 'Clementina'; TSK: tangerineira 'Sunki'; LCR: limoeiro 'Cravo'; LVK: limoeiro 'Volkameriano'; LAC: laranjeira 'Azeda Comum'; LADC: laranjeira 'Azeda Double Calice'. (2)Dados obtidos de Vásquez Araujo (1991). ${ }^{(3)}$ Dados obtidos de Moreira (1996).

Tabela 7. Porcentagens relativas (R) de indivíduos trifoliados (IT) obtidas a partir das freqüências desses indivíduos observadas no cultivo in vitro de embriões (CIV) e no cultivo de sementes em canteiros (CSC), referentes a seis variedades cítricas. Cruz das Almas, BA, 1996-1997.

\begin{tabular}{lllr}
\hline Variedade $^{(1)}$ & CIV & CSC & $\mathrm{R}^{(2)}$ \\
\hline TCL & 56,2 & 51,5 & 8,4 \\
TSK & 51,1 & 48,6 & 4,9 \\
LCR & $18,6^{(3)}$ & 16,2 & 12,9 \\
LVK & 16,3 & 11,9 & 27,0 \\
LAC & 17,4 & 12,2 & 29,9 \\
LADC & 13,1 & 11,2 & 14,5 \\
\hline
\end{tabular}

(1)TCL: tangerineira 'Clementina'; TSK: tangerineira 'Sunki'; LCR: limoeiro 'Cravo'; LVK: limoeiro 'Volkameriano'; LAC: laranjeira 'Azeda Comum'; LADC: laranjeira 'Azeda Double Calice' ${ }^{(2)} \mathrm{R}=100(\mathrm{CIV}-\mathrm{CSC}) / \mathrm{CIV}$. ${ }^{(3)}$ Valor obtido de estudos realizados por Vásquez Araujo (1991) e Moreira (1996)
A freqüência observada de híbridos nesta pesquisa está subestimada, em razão da utilização de híbridos de Poncirus (citanges 'Argentina', 'Troyer', 'Rusk' e C-35, além do citrumelo 'Swingle') como parentais masculinos, implicando segregações da característica trifoliada, determinando a formação de híbridos com limbo foliar simples, não identificados visualmente.

\section{Conclusões}

1. A presença dos tegumentos das sementes implica aumentos no período de germinação.

2. A eliminação dos tegumentos das sementes não determina alterações expressivas na porcentagem de germinação.

3. O cultivo in vitro de embriões de variedades com graus elevados de poliembrionia $(>70 \%)$ é preferível ao cultivo de sementes em canteiros, por permitir maior sobrevivência de híbridos.

\section{Referências}

CAMERON, J. W.; SOOST, R. K. Citrus. In: SIMMONDS, N. W. (Ed.). Evolution of crop plants. New York: Longuran, 1976. p. 261-265.

CAMERON, J. W.; SOOST, R. K. Sexual and nucellar embryony in $\mathrm{F}_{1}$ hybrids and advanced crosses of Citrus with Poncirus. Journal of the American Society for Horticultural Science, Alexandria, v. 104, n. 3, p. 408410, 1979.

DIAZ, E. D. L.; XIQUES, X.; CAPIRO, N.; LIMA, H. La poliembrionia en el género Citrus. Ciencia y Técnica en la Agricultura, Serie Cítricos y Otros Frutales, Havana, v. 2, n. 1, p. 95-104, 1979.

DUBEY, K. C.; RISHI, N. Studies on the nucellar embryos of some cultivated citrus species. Horticultural Research, Edinburgh, v. 15, n. 2, p. 49-52, 1976.

FROST, H. B.; SOOST, R. K. Seed reproduction: development of gametes and embryos. In: REUTHER, W.; BATCHELOR, L. D.; WEBBER, H. J. (Ed.). The citrus industry. Berkeley: University of California, 1968. v. 2 , p. $290-324$.

MOREIRA, C. S. Freqüência de híbridos em citros (Citrus spp.) em relação ao grau de poliembrionia. 1996. 78 f. Dissertação (Mestrado) - Universidade Federal da Bahia, Cruz das Almas. 1996. 
MOREIRA, S.; GURGEL, J. T. A fertilidade do pólen e sua correlação com o número de sementes em espécies e formas do gênero Citrus. Bragantia, Campinas, v. 1, p. 660-711, 1941.

MOREIRA, S.; GURGEL, J. T.; ARRUdA, L. F. Poliembrionia em citrus. Bragantia, Campinas, v. 7, n. 3, p. 69-106, 1947.

MURASHIGE, T.; TUCKER, D. P. H. Growth factor requirement of citrus tissue culture. In: INTERNATIONAL CITRUS SYMPOSIUM, 1., 1968, Riverside. Proceedings... Riverside: University of California, 1969. v. 3, p. 1155-1161.

NAKATANI, M.; IKEDA, I.; KOBAYASHI, S. Studies on an effective method for getting hybrid seedlings in polyembryonic citrus. II. Difference of the numbers of embryos per seed in strains of Satsuma madarin (Citrus unshiu Marc.). Bulletin of the Fruit Tree Research Station, Tsukuba, v. 3, p. 15-23, 1980.

PARLEVLIET, J. E.; CAMERON, J. W. Evidence on the inheritance of nucellar embryony in citrus. Proceedings of the American Society for Horticultural Science, Beltsville, v. 74, p. 252-260, 1959.

SOARES FILHO, W. dos S.; LEE, L. M.; CUNHA SOBRINHO, A. P. da. Influence of pollinators on polyembryony in citrus. Acta Horticulturae, Wageningen, n. 403 , p. $256-265,1995$ a.

SOARES FILHO, W. dos S.; MOREIRA, C. dos S.; CUNHA, M. A. P. da; CUNHA SOBRINHO, A. P. da; PASSOS, O. S. Poliembrionia e freqüência de híbridos em
Citrus spp. Pesquisa Agropecuária Brasileira, Brasília, v. 35, n. 4, p. 857-864, abr. 2000.

SOARES FILHO, W. dos S.; PELACANI, C. R.; SOUZA, A. da S.; CUNHA SOBRINHO, A. P. da; ARAÚJO, E. F. Influência dos tegumentos externo e interno na germinação de sementes de citros: implicações na sobrevivência de "seedlings" híbridos. Revista Brasileira de Fruticultura, Cruz das Almas, v. 17, n. 1, p. 91101, 1995b.

SOARES FILHO, W. dos S.; VÁSQUEZ ARAUJO, J. E.; CUNHA, M. A. P. da; CUNHA SOBRINHO, A. P. da; PASSOS, O. S. Degree of polyembryony, size and survival of the zygotic embryo in citrus. In: INTERNATIONAL CITRUS CONGRESS, 7., 1992, Acireale. Proceedings... Catania: International Society of Citriculture, 1994. v. 1, p. $135-138$.

SOARES FILHO, W. dos S.; VÁSQUEZ ARAUJO, J. E.; CUNHA, M. A. P. da; CUNHA SOBRINHO, A. P. da; PASSOS, O. S. Variabilidade genética em limão 'Cravo'. Revista Brasileira de Fruticultura, Cruz das Almas, v. 13 , n. 3, p. 267-272, 1991.

VÁSQUEZ ARAUJO, J. E. Identificação de embriões zigóticos em sementes poliembriônicas de citros (Citrus spp.) mediante características morfológicas. 1991. 74 f. Dissertação (Mestrado) - Universidade Federal da Bahia, Cruz das Almas. 1991.

VIEIRA, D. V.; CARVALHO, N. M. Testes de vigor em sementes. Jaboticabal: Funep, 1994. 164 p.

WONG, C. Y. The influence of pollination on seed development in certain varieties of citrus. Journal of the American Society for Horticultural Science, v. 37, p. 161-164, 1939. 